OPEN ACCESS

Edited by:

Brian McCool,

Wake Forest School of Medicine,

United States

Reviewed by:

David M. Lovinger,

National Institute on Alcohol Abuse and Alcoholism (NIAAA), United States

Enrico Sanna

Università degli studi di Cagliari, Italy

Carlos Fernando Valenzuela

University of New Mexico,

United States

*Correspondence:

Joel E. Shillinglaw joeleshillinglaw@gmail.com

Regina A. Mangieri

reginamangieri@utexas.edu

${ }^{\dagger}$ deceased

¥Share senior authorship

Specialty section:

This article was submitted to

Neuropharmacology,

a section of the journal

Frontiers in Pharmacology

Received: 05 September 2018 Accepted: 29 November 2018 Published: 18 December 2018

Citation: Shillinglaw JE, Morrisett RA and Mangieri RA (2018) Ethanol Modulates

Glutamatergic Transmission and NMDAR-Mediated Synaptic Plasticity in the Agranular Insular Cortex. Front. Pharmacol. 9:1458. doi: 10.3389/fphar.2018.01458

\section{Ethanol Modulates Glutamatergic Transmission and NMDAR-Mediated Synaptic Plasticity in the Agranular Insular Cortex}

\author{
Joel E. Shillinglaw ${ }^{*}$, Richard A. Morrisett ${ }^{\ddagger \neq}$ and Regina A. Mangieri ${ }^{* \neq}$ \\ Division of Pharmacology and Toxicology, College of Pharmacy, The University of Texas at Austin, Austin, TX, United States
}

The agranular insular cortex (AIC) has recently been investigated by the alcohol field because of its connectivity to and modulatory control over limbic and brainstem regions implicated in alcohol use disorder (AUD), and because it has shown involvement in animal models of alcohol drinking. Despite evidence of AIC involvement in AUD, there has not yet been an examination of whether ethanol modulates glutamatergic and $\gamma$-amino-butyric acid (GABA)ergic synaptic transmission and plasticity in the AIC. Characterizing how the synaptic transmission and plasticity states of AIC cortical processing neurons are modulated by acute ethanol will likely reveal the molecular targets by which chronic ethanol alters AIC function as alcohol drinking transitions from controlled to problematic. Therefore, we collected brain slices from ethanol-naive adult male mice, obtained whole-cell recording configuration in layer 2/3 AIC pyramidal neurons, and bath-applied ethanol at pharmacologically relevant concentrations during electrophysiological assays of glutamatergic and GABAergic synaptic transmission and plasticity. We found that ethanol inhibited electrically evoked N-methyl-D-aspartate receptor (NMDAR)-mediated excitatory post-synaptic currents (EPSCs) in a concentration-related fashion, and had little effect on evoked $\alpha$-amino-3-hydrox-5-methylisoxazole-4-propionic acid-type receptor (AMPAR)-mediated EPSCs. Ethanol had no effect on spontaneous excitatory post-synaptic currents (sEPSCs) or inhibitory $\mathrm{GABA}_{A}$ R-mediated post-synaptic currents (SIPSCs). We found that synaptic conditioning (low-frequency stimulation for $15 \mathrm{~min}$ at $1 \mathrm{~Hz}$ ) induced a form of long-term depression (LTD) of evoked AMPAR-mediated EPSCs. The ability to induce LTD was inhibited by a non-selective NMDAR antagonist (DL-2-amino-5-phosphonovaleric acid), and also by acute, intoxicating concentrations of ethanol. Taken together these data suggest that the glutamate, but not GABA system in the AIC is uniquely sensitive to ethanol, and that in particular NMDAR-mediated processes in the AIC may be disrupted by pharmacologically relevant concentrations of ethanol.

Keywords: electrophysiology, ethanol, glutamate, synaptic plasticity, insular cortex, mouse 


\section{INTRODUCTION}

Despite several years of preclinical research investigating the mechanisms underlying the transition from controlled to problematic alcohol drinking in order to develop future therapeutic approaches, alcohol use disorder (AUD) remains one of the most prevalent and costly health problems in the United States (Stahre et al., 2014; Sacks et al., 2015). Current pharmacological and behavioral treatments have achieved only moderate success largely due to their inability to decrease the vulnerability to relapse in abstinent addicts (Scofield et al., 2016). Therefore, investigating the neural networks implicated in the craving and relapse components of AUD is vital to developing more efficacious treatment options. Recent research suggests that deficits in interoceptive processing, or the processing and integration of physiological bodily states, may in part contribute to craving and relapse components of substance use disorders (Paulus and Stewart, 2014).

The agranular insular cortex (AIC) is a brain region implicated in interoceptive processing, and altered AIC function and output to subcortical limbic regions has been shown to mediate alcohol intake in animal models of AUD (Seif et al., 2013; Jaramillo et al., 2016, 2018a,b). Yet despite evidence for altered AIC function and output in AUD, there has been no investigation of whether the AIC is an ethanol-sensitive brain region in which basic synaptic functions are modulated by pharmacologically relevant concentrations of acute ethanol. It is widely accepted that the synapse is sensitive to ethanol, and that ethanol's major pharmacodynamic effects occur at least in part via its modulatory actions on the major fast excitatory and inhibitory neurotransmitter systems, glutamate and gamma-aminobutyric acid (GABA), respectively. However, these synaptic actions have been shown to be both brain region and concentrationdependent (Lovinger et al., 1990; Nie et al., 1994; Roberto et al., 2003; Kash et al., 2008; Weitlauf and Woodward, 2008; Badanich et al., 2013).

Moreover, the synaptic targets of acute ethanol have generally displayed opposing or compensatory effects after chronic ethanol exposure in animal models designed to mimic long-term alcohol abuse (Lovinger and Roberto, 2013). These compensatory effects of chronic ethanol on synaptic receptors have been shown to encode long-term alterations in glutamatergic and GABAergic transmission and to underlie, in part, aspects of AUD, such as withdrawal, tolerance and dependence (Jeanes et al., 2011; Lovinger and Roberto, 2013; Lovinger and Kash, 2015; Renteria et al., 2017). We therefore suggest that any synaptic target in the AIC that is sensitive to acute ethanol may be a target by which chronic ethanol disrupts AIC function as chronic ethanol shifts alcohol drinking from controlled to problematic.

For these reasons we investigated the effects of acute ethanol on pharmacologically isolated glutamatergic and GABAergic synaptic transmission, and an $\mathrm{N}$-methyl D-aspartate-type glutamate receptor (NMDAR)-dependent glutamatergic synaptic plasticity in mouse AIC. We decided to investigate layer $2 / 3$ pyramidal neurons since layer $2 / 3$ of the cortex is generally considered the intracortical processing layer. We found that NMDAR-mediated currents were inhibited by pharmacologically relevant concentrations of ethanol. Conversely, alpha-amino3-hydroxy-5-methylisoxazole-4-propionic acid-type glutamate receptor (AMPAR)-mediated currents were insensitive to ethanol. Ethanol had no effect on spontaneous excitatory post-synaptic currents (sEPSCs) or spontaneous inhibitory $\gamma$ amino-butyric acid receptor (GABAR)-mediated post-synaptic currents (sIPSCs). Our investigated form of synaptic plasticity, NMDAR-dependent long-term depression (LTD), was sensitive to pharmacologically relevant concentrations of ethanol. These findings are the initial demonstration that the AIC is a direct synaptic target for the actions of ethanol, and that glutamatergic transmission and plasticity, but not GABAergic transmission, is sensitive to pharmacologically relevant concentrations of acute ethanol.

\section{METHODS}

\section{Preparation of Brain Slices}

Mice were briefly anesthetized with isoflurane, euthanized by decapitation, and then brains were rapidly extracted and placed in ice-cold oxygenated artificial cerebrospinal fluid (ACSF) containing the following (in $\mathrm{mM}$ ): 210 Sucrose, $26.2 \mathrm{NaHCO}_{3}$, $1 \mathrm{NaH}_{2} \mathrm{PO}_{4}, 2.5 \mathrm{KCl}, 11$ dextrose, bubbled with 95\% $\mathrm{O}_{2} / 5 \%$ $\mathrm{CO}_{2}$. Coronal slices (230 to $250 \mu \mathrm{m}$ thick) containing the most anterior portion of the AIC (anterior-posterior $=+2.46$ to +1.54) were then collected in ice-cold oxygenated ACSF using a Leica VT1000S vibrating microtome (Leica Corp., Bannockburn, IL). Slices were then transferred into an incubation solution containing the following (in $\mathrm{mM}$ ): $120 \mathrm{NaCl}, 25$ $\mathrm{NaHCO}_{3}, 1.23 \mathrm{NaH}_{2} \mathrm{PO}_{4}, 3.3 \mathrm{KCl}, 2.4 \mathrm{MgCl}_{2}, 1.8 \mathrm{CaCl}_{2}, 10$ dextrose, continuously bubbled with $95 \% \mathrm{O}_{2} / 5 \% \mathrm{CO}_{2} ; 32^{\circ} \mathrm{C}$, and maintained in this solution at least $45 \mathrm{~min}$ prior to recording.

\section{Patch-Clamp Electrophysiology}

Whole cell voltage clamp recordings were made in layer $2 / 3$ pyramidal AIC neurons from anterior-posterior $=+2.46$ to +1.54 . Pyramidal neurons were identified based on morphology (large, pyramidal shape) using a MRK200 Modular Imaging system (Siskiyou Corporation, Grants Pass, OR) mounted on a vibration isolation table. Passive electrical membrane properties for each cell at the beginning and end of each experiment are provided in Tables 1-7. Recordings were made in ACSF containing (in mM): $120 \mathrm{NaCl}, 25 \mathrm{NaHCO}_{3}, 1.23 \mathrm{NaH}_{2} \mathrm{PO}_{4}, 3.3$ $\mathrm{KCl}, 1.2 \mathrm{MgSO}_{4}, 2.0 \mathrm{CaCl}_{2}$, and 10 dextrose unless otherwise noted, bubbled with $95 \% \mathrm{O}_{2} / 5 \% \mathrm{CO}_{2} ; 32^{\circ} \mathrm{C}$, controlled by an inline bath heather (Warner Instruments, Hamden, CT). The bath ACSF perfused brain slices at a rate of $2.0 \mathrm{~mL} / \mathrm{min}$. Recording electrodes (thin-wall glass, WPI Instruments, Sarasota FL) were made using a P-97 Flaming/Brown model micropipette puller (Sutter Instruments, San Rafael, CA) which produced electrodes of resistances from 3 to $6 \mathrm{M} \Omega$. Series resistance (Rs) was monitored throughout the duration of each experiment and cells with Rs of over $30 \mathrm{M} \Omega$ or that changed over $20 \%$ over the course of the experiment were excluded from the analysis.

All chemicals, unless otherwise noted, were obtained from Sigma-Alrich or Tocris Bioscience with the exception of ethanol, which was obtained from Pharmco-Aaper. Multiple cells per 

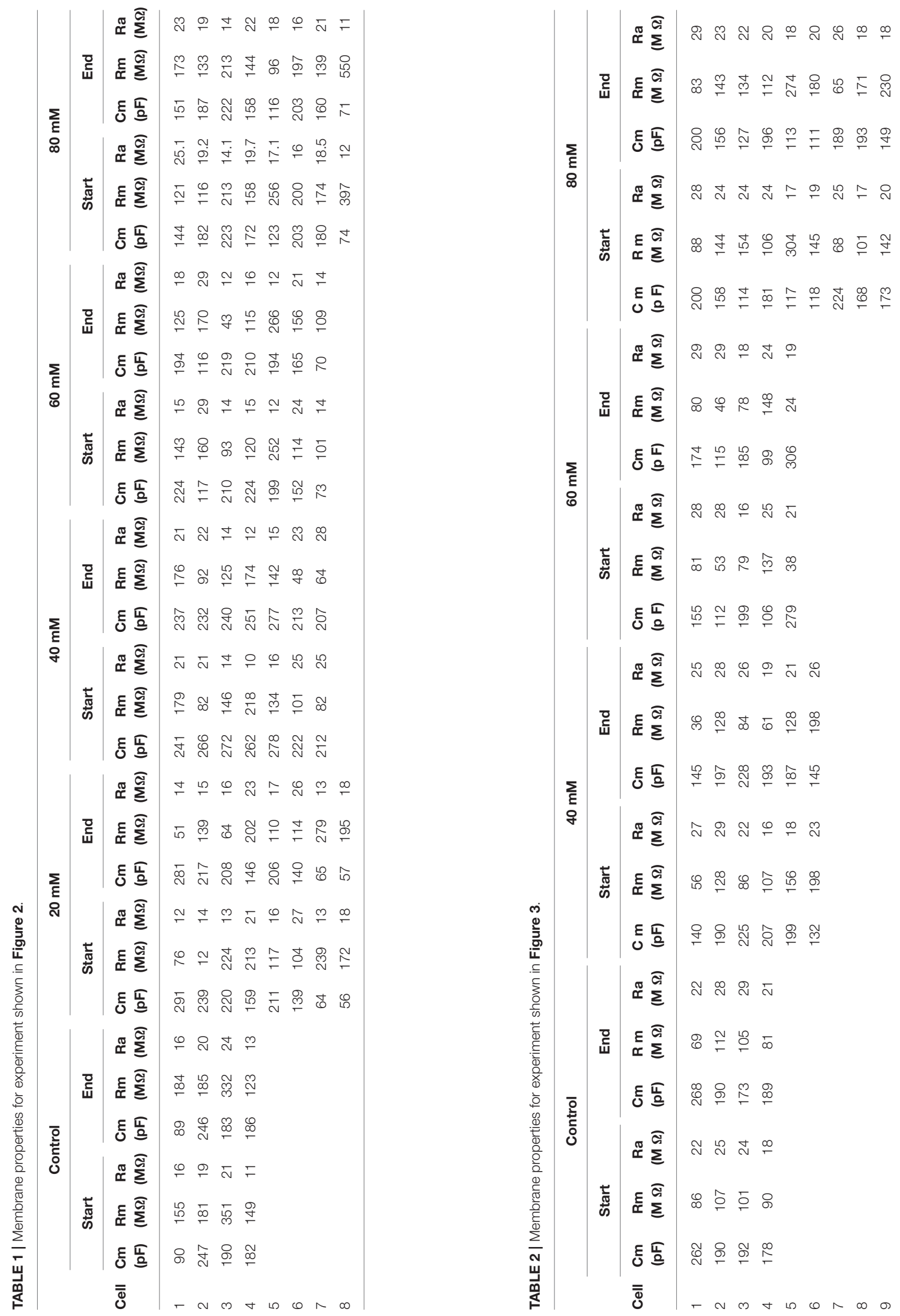
TABLE 3 | Membrane properties for experiment shown in Figure 4.

\begin{tabular}{|c|c|c|c|c|c|c|c|c|c|c|c|c|}
\hline \multirow[b]{2}{*}{ Cell } & \multicolumn{6}{|c|}{ Control } & \multicolumn{6}{|c|}{$50 \mathrm{mM}$} \\
\hline & $\begin{array}{l}\mathrm{Cm} \\
\text { (pF) }\end{array}$ & $\begin{array}{l}\mathrm{Rm} \\
\text { (M } \Omega \text { ) }\end{array}$ & $\begin{array}{c}\mathbf{R a} \\
\text { (M } \Omega \text { ) }\end{array}$ & $\begin{array}{l}\mathrm{Cm} \\
(\mathrm{pF})\end{array}$ & $\begin{array}{l}\mathrm{Rm} \\
\text { (M } \Omega \text { ) }\end{array}$ & $\begin{array}{c}\mathrm{Ra} \\
\text { (M } \Omega \text { ) }\end{array}$ & $\begin{array}{l}\mathrm{Cm} \\
(\mathrm{pF})\end{array}$ & $\begin{array}{l}\text { Rm } \\
\text { (M } \Omega \text { ) }\end{array}$ & $\begin{array}{c}\text { Ra } \\
\text { (M } \Omega \text { ) }\end{array}$ & $\begin{array}{l}\mathrm{Cm} \\
(\mathrm{pF})\end{array}$ & $\begin{array}{l}\mathrm{Rm} \\
(\mathrm{M} \Omega \text { ) }\end{array}$ & $\begin{array}{c}\mathbf{R a} \\
\text { (M } \Omega)\end{array}$ \\
\hline 1 & 233 & 129 & 23 & 215 & 127 & 25 & 228 & 179 & 20 & 166 & 70 & 17 \\
\hline 2 & 205 & 114 & 27 & 192 & 127 & 29 & 159 & 341 & 23 & 146 & 74 & 21 \\
\hline 4 & 222 & 95 & 26 & 226 & 98 & 25 & 210 & 164 & 25 & 188 & 218 & 27 \\
\hline 5 & 216 & 212 & 16 & 207 & 70 & 16 & 259 & 108 & 21 & 222 & 119 & 25 \\
\hline 6 & 71 & 416 & 27 & 65 & 458 & 24 & 300 & 107 & 19 & 256 & 88 & 19 \\
\hline 7 & 256 & 78 & 23 & 229 & 96 & 25 & 89 & 59 & 22 & 80 & 57 & 18 \\
\hline 8 & 206 & 23 & 24 & 216 & 32 & 25 & 205 & 143 & 26 & 190 & 116 & 26 \\
\hline
\end{tabular}

TABLE 4 | Membrane properties for experiment shown in Figure 5.

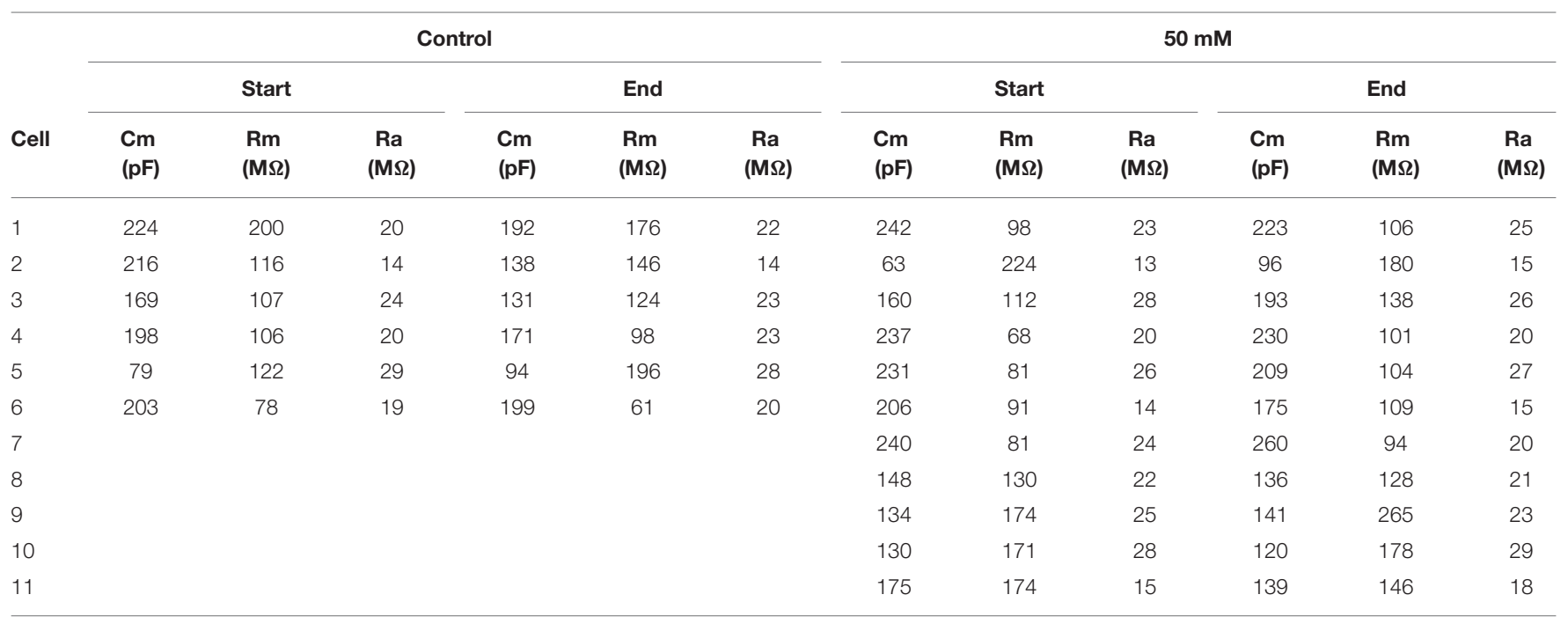

brain slice were sometimes recorded from in glutamatergic and GABAergic transmission experiments, but only when the first cell recorded from was assigned to the time and sham solution exchange control condition. Thus, the final recording for each brain slice occurred once the slice was exposed to ethanol. For LTD experiments, only one cell per brain slice was used.

\section{Evoked Glutamatergic Transmission}

For evoked excitatory (NMDAR-mediated) post-synaptic currents, recording electrodes were filled with (in $\mathrm{mM}$ ): $120 \mathrm{CsMeSO}_{4}, 15 \mathrm{CsCl}, 8 \mathrm{NaCl}, 10$ HEPES, 0.2 EGTA, 10 TEA-Cl, 4 Mg-ATP, 0.3 Na-GTP, 0.1 Spermine, and 5 QX314-Cl. DNQX $(20 \mu \mathrm{M})$ was added to the recording ACSF to block AMPA receptors, along with picrotoxin $(50 \mu \mathrm{M})$ to block $\mathrm{GABA}_{\mathrm{A}}$ receptors. The recording ACSF for evoked NMDAR-mediated experiments contained $1.0 \mathrm{mM} \mathrm{MgSO}_{4}$, and EPSCs were evoked by local stimulation while holding the post-synaptic membrane voltage at $-40 \mathrm{mV}$ for $2.4 \mathrm{~s}$. For evoked excitatory (AMPAR-mediated) post-synaptic currents, recording electrodes were filled with (in $\mathrm{mM}$ ): $120 \mathrm{~K}$-gluconate, $10 \mathrm{KCl}, 10 \mathrm{HEPES}, 2 \mathrm{MgCl}_{2}, 1 \mathrm{EGTA}, 2 \mathrm{Mg}$-ATP, and 0.3 Tris-GTP. DL-APV $(100 \mu \mathrm{M})$ was added to the recording ACSF to block NMDA receptors, along with picrotoxin $(50 \mu \mathrm{M})$. Neurons in evoked AMPAR-mediated experiments were held at $-70 \mathrm{mV}$ for the entirety of the experiment. For both evoked AMPAR-mediated and NMDAR-mediated post-synaptic current experiments, standard evoked EPSCs were established for at least $8 \mathrm{~min}$ (at $0.025 \mathrm{~Hz}$ ) to ensure stable recordings, followed by $10 \mathrm{~min}$ periods of ethanol treatment and ethanol washout. Additional validation experiments were conducted to confirm that the currents under investigation were mediated by the receptors of interest. Evoked NMDA-mediated synaptic currents were reduced in amplitude by $\approx 78 \%$ by $100 \mu \mathrm{M}$ DL-APV, and evoked AMPAR-mediated synaptic currents were reduced in amplitude by $\approx 93 \%$ by $20 \mu \mathrm{M}$ DNQX (data not shown). 
TABLE 5 | Membrane properties for experiment shown in Figure 6.

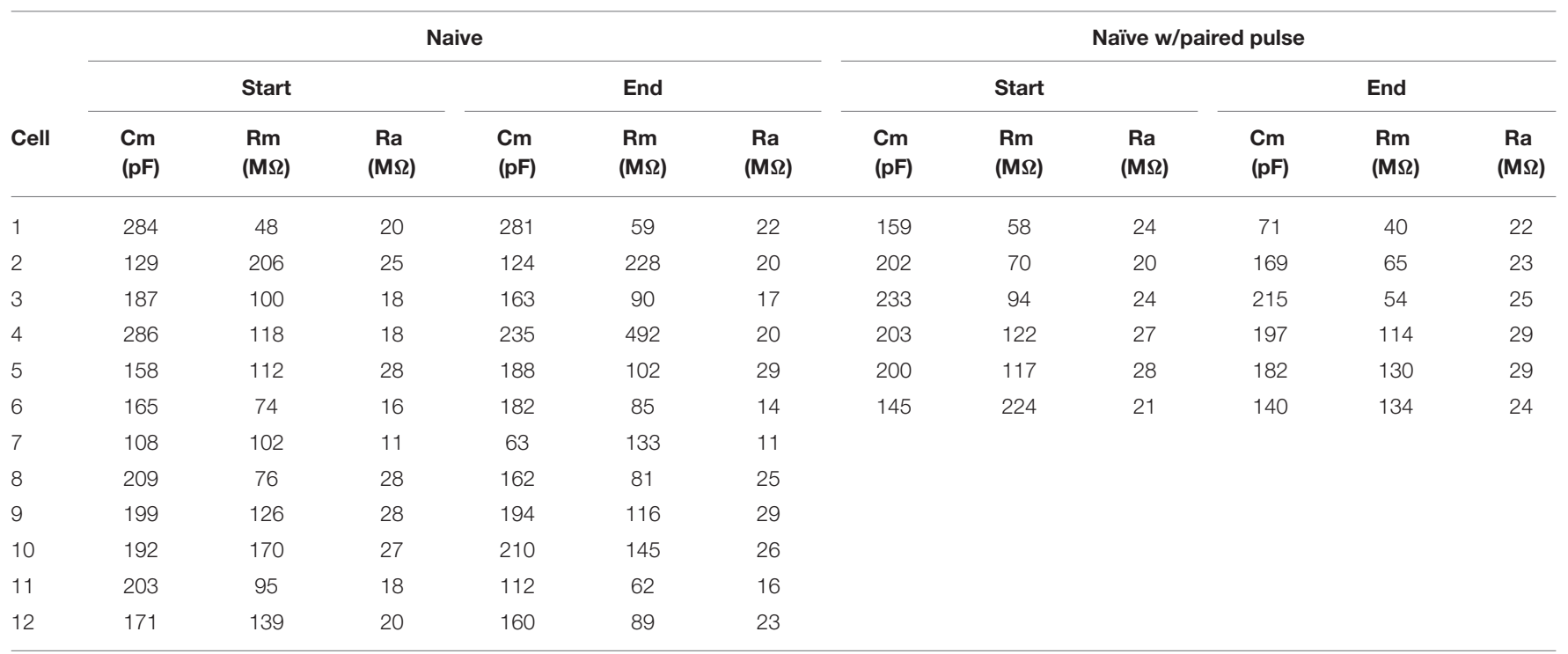

TABLE 6 | Membrane properties for experiment shown in Figure 7.

\begin{tabular}{|c|c|c|c|c|c|c|}
\hline \multirow[b]{3}{*}{ Cell } & \multicolumn{5}{|c|}{ DL-APV } & \\
\hline & \multicolumn{3}{|c|}{ Start } & \multicolumn{3}{|c|}{ End } \\
\hline & $\begin{array}{l}\mathrm{Cm} \\
(\mathrm{pF})\end{array}$ & $\begin{array}{l}\mathrm{Rm} \\
\text { (M } \Omega \text { ) }\end{array}$ & $\begin{array}{l}\text { Ra } \\
\text { (M } \Omega \text { ) }\end{array}$ & $\begin{array}{l}\text { Cm } \\
\text { (pF) }\end{array}$ & $\begin{array}{l}\mathrm{Rm} \\
\text { (M } \Omega \text { ) }\end{array}$ & $\begin{array}{l}\mathrm{Ra} \\
\text { (M } \Omega \text { ) }\end{array}$ \\
\hline 1 & 177 & 192 & 29 & 176 & 116 & 29 \\
\hline 2 & 138 & 107 & 21 & 91 & 123 & 21 \\
\hline 3 & 154 & 91 & 21 & 161 & 97 & 24 \\
\hline 4 & 194 & 286 & 19 & 183 & 308 & 19 \\
\hline 5 & 174 & 195 & 29 & 192 & 208 & 26 \\
\hline 6 & 184 & 92 & 28 & 179 & 83 & 25 \\
\hline 7 & 331 & 79 & 17 & 279 & 117 & 193 \\
\hline
\end{tabular}

\section{Spontaneous Glutamatergic and GABAergic Transmission}

For spontaneous excitatory post-synaptic currents (sEPSCs), recording electrodes were filled with (in $\mathrm{mM}$ ): $135 \mathrm{KMeSO}_{4}$, $12 \mathrm{NaCl}, 0.5$ EGTA, 10 HEPES, $2 \mathrm{Mg}$-ATP, and 0.3 TrisGTP. Picrotoxin $(50 \mu \mathrm{M})$ was added to the recording ACSF. For spontaneous inhibitory post-synaptic currents (sIPSCs), recording electrodes were filled with (in $\mathrm{mM}$ ): $120 \mathrm{CsCl}$, 10 HEPES, $2 \mathrm{MgCl}_{2}$, 1 EGTA, $2 \mathrm{Mg}$-ATP, 0.3 Tris-GTP, and 1 QX-314. Kynurenic acid $(1 \mathrm{mM})$ was added to the recording ACSF to block AMPA and NMDA receptors. For both spontaneous excitatory and inhibitory post-synaptic current experiments, neurons were held at $-70 \mathrm{mV}$ for $10 \mathrm{~min}$ to ensure stable recordings, followed by $10 \mathrm{~min}$ periods of ethanol treatment and ethanol washout. Additional validation experiments were conducted to confirm that the currents under investigation were mediated by the receptors of interest. sEPSCs were reduced in frequency by $\approx 93 \%$ by $1 \mathrm{mM}$ kynurenic acid, and sIPSCs were reduced in frequency by $\approx 95 \%$ by $50 \mu \mathrm{M}$ picrotoxin (data not shown).

\section{Synaptic Plasticity}

For LTD synaptic plasticity experiments, recording electrodes were filled with (in mM): $120 \mathrm{~K}$-gluconate, $10 \mathrm{KCl}, 10 \mathrm{HEPES}, 2$ $\mathrm{MgCl}_{2}, 1$ EGTA, $2 \mathrm{Mg}$-ATP, and 0.3 Tris-GTP. Neurons were held at $-70 \mathrm{mV}$ for the entirety of the experiment, and the ACSF was supplemented with picrotoxin $(50 \mu \mathrm{M})$. Standard evoked EPSCs were established for at least $10 \mathrm{~min}$ (at $0.025 \mathrm{~Hz}$ ) to ensure stable recordings, and then followed by a low-frequency stimulation protocol consisting of $1 \mathrm{~Hz}$ stimulation for $15 \mathrm{~min}$. Evoked EPSCs were then monitored for a $30 \mathrm{~min}$ post-stimulation period at $0.025 \mathrm{~Hz}$ to test for the expression of LTD.

\section{Data Acquisition and Analysis}

All currents were acquired using an Axopatch 200B amplifier (Axon Instruments, Foster City, CA), filtered at $1 \mathrm{kHz}$, and digitized at $10-20 \mathrm{kHz}$ via a Digidata $1440 \mathrm{~A}$ interface board using pClamp 10.2 (Axon Instruments). In spontaneous experiments, sEPSCs and sIPSCs were recorded for $30 \mathrm{~min}$ and separated into 198 consecutive sweeps; events $>5 \mathrm{pA}$ and $10 \mathrm{pA}$ were analyzed in sEPSC and sIPSC experiments, respectively, for mean frequency and mean amplitude. For all evoked experiments, post-synaptic currents (100-200 pA) were evoked via either theta glass electrode or a stainless steel bipolar stimulating electrode (MX21AES, FHC, Inc., Bowdoin, ME, United States) placed $\sim 500 \mu \mathrm{m}$ dorsomedial to the cell body (Figure 1).

For all experiments investigating acute ethanol on GABAergic and glutamatergic transmission, we used two approaches to statistical analysis. First, a General Linear Model Repeated Measures in IBM SPSS Advanced Statistics 23 was used, with time or phase of the experiment as the repeated measure, and 


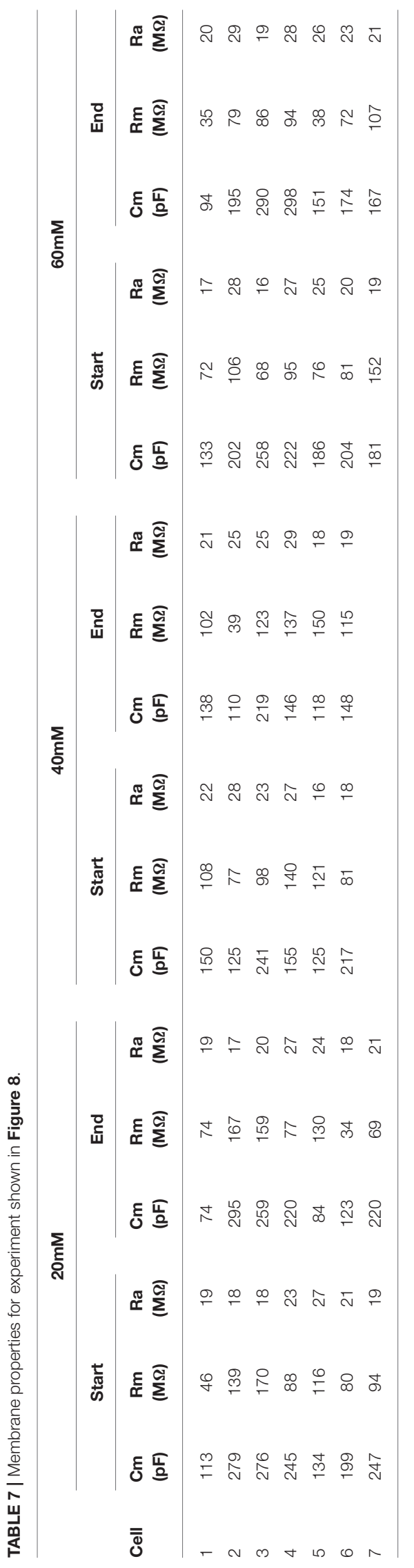

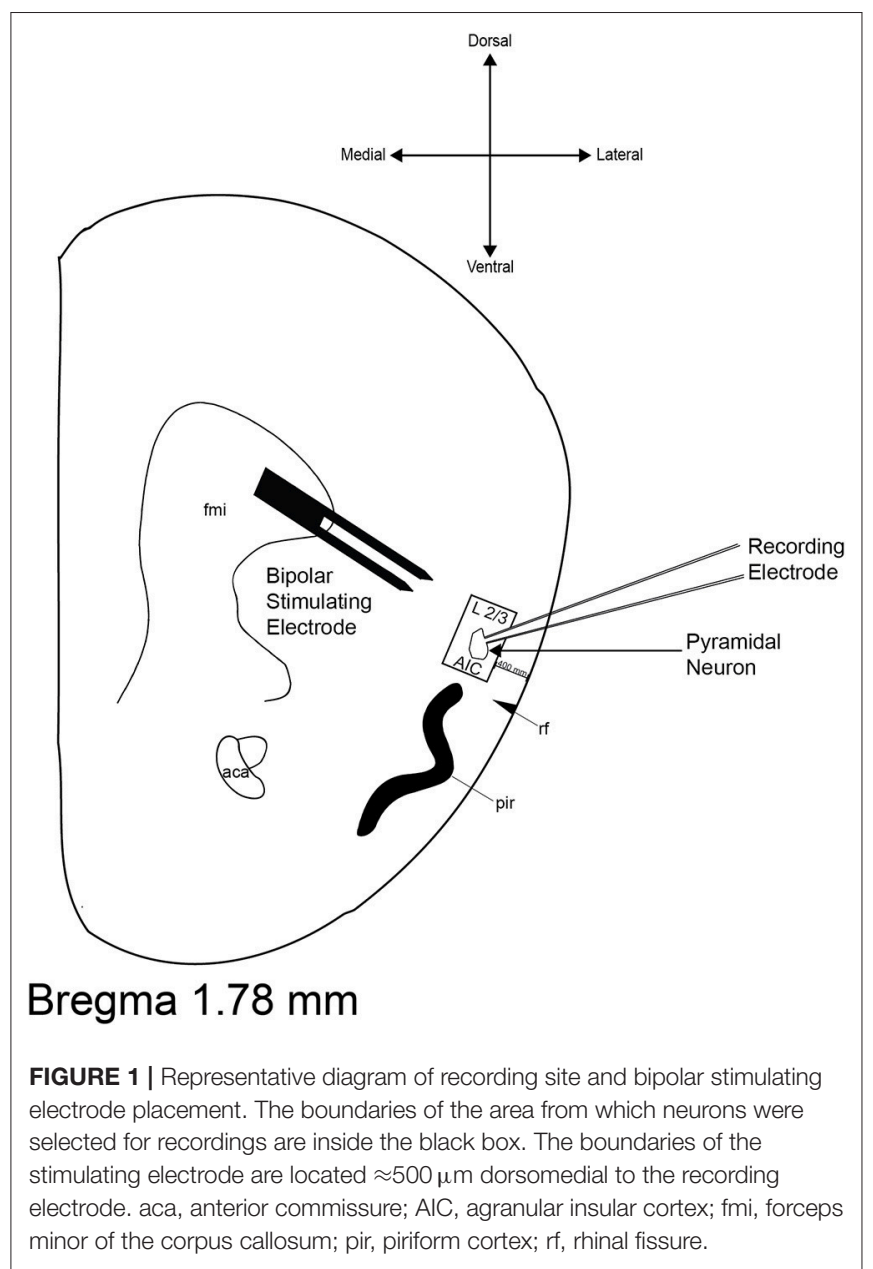

treatment condition (ethanol concentration) as the betweengroups factor. For evoked currents, we analyzed the entire time course of the experiment, with 28 levels of the repeated measure (time), and 4 levels (eNMDAR) or 5 levels (eAMPAR) of the between-groups factor (treatment condition). For spontaneous currents, we used phase of the experiment as the repeated measure (3 levels: baseline, treatment, and washout) and treatment condition as the between-groups factor (2 levels). When sphericity within groups was violated (as indicated by Mauchly's test), the Greenhouse-Geisser adjusted degrees of freedom and $p$-values were reported in the text, rounded to the nearest whole number. Second, we also analyzed the effects of ethanol on evoked and spontaneous currents without the use of a repeated measure. We used a 1-way between groups ANOVA to compare treatment conditions during a particular phase of the experiment-either the treatment phase (for evoked NMDAR) or the washout phase (for evoked AMPAR). These were followed by Bonferroni-corrected multiple comparisons. For spontaneous currents, we performed between groups analysis ( $t$-test) to compare treatment conditions during just the treatment phase.

GraphPad Prism 8.0 was used to analyze LTD experiments. The expression of LTD was determined by comparing the 20 to $30 \mathrm{~min}$ period after the low-frequency stimulation protocol to 
the $10 \mathrm{~min}$ baseline period. Statistical significance from baseline for within each treatment group was defined as $p<0.05$ using a one-sample $t$-test. Group comparisons for LTD experiments were made using a one-way ANOVA and Bonferroni post-hoc test. Statistical significance for all experiments was defined as $p$ $<0.05$.

\section{Mice}

Ethanol-naïve Drd1a-tdTomato BAC transgenic male mice (MMRRC: 030512-UNC) of at least 7 weeks of age were used for all experiments. Briefly, an existing colony of Drd1a-tdTomato mice (Ade et al., 2011; initial breeding pairs obtained from The Jackson Laboratory, Stock No. 016204) was maintained by backcrossing mice onto a C57BL/6J background in which only one parent carried the Drd1a-tdTomato transgene (as described in Mangieri et al., 2017). Mice were group-housed (up to five mice per cage) in standard cages $\left(7.5^{\prime \prime} \times 11.5^{\prime \prime} \times 5^{\prime \prime}\right)$ with SaniChips wood bedding (PJ Murphy) at $22^{\circ} \mathrm{C}$ with a $12: 12$ light: dark cycle (lights off at 9:30AM). Water and standard chow (LabDiet ${ }^{\circledR}$ 5LL2 Prolab RMH1800) were available ad libitum, and all experimental procedures were approved by the University of Texas Institutional Animal Care and Use Committee.

\section{RESULTS}

\section{Ethanol-Sensitivity of Evoked NMDA-Type Glutamatergic Transmission}

NMDAR-mediated currents were evoked for $8 \mathrm{~min}$ to ensure steady baseline responses before slices were perfused with an ethanol-containing ACSF for a 10 min treatment period, followed by a $10 \mathrm{~min}$ ethanol washout period (Figure 2). When analyzed over the entire $28 \mathrm{~min}$ experiment, we observed that the effect of time on NMDAR-mediated EPSC amplitude was not uniform, but varied with the treatment condition [two-way repeated measures ANOVA, main effect of time: $F_{(3,86)}=4.7, p=$ 0.004; time $\times$ treatment interaction: $F_{(12,86)}=2.3, p=0.013$ ], indicating that the changes in EPSC amplitude over the course of the experiment were not due to time alone. This conclusion was further supported by a significant between-groups effect during the treatment period $\left[F_{(4,29)}=8.1, p<0.001\right]$, when higher concentrations of ethanol $(\geq 40 \mathrm{mM})$ all displayed significant reduction of peak NMDAR-mediated response relative to control (Figure 2C).

\section{Ethanol-Sensitivity of Evoked AMPAR-Type Glutamatergic Transmission}

Ethanol has been shown to inhibit NMDAR-mediated currents across several brain regions, but has also been shown to inhibit AMPAR-mediated currents (Lovinger and Roberto, 2013). In order to test the sensitivity of AMPAR-mediated currents to ethanol, we tested whether ethanol modulated evoked AMPAR-mediated transmission. Therefore, neurons were voltage-clamped at $-70 \mathrm{mV}$, and EPSCs were evoked in the presence of $100 \mu \mathrm{M}$ DL-APV and $50 \mu \mathrm{M}$ picrotoxin to isolate AMPAR-mediated currents. Following $8 \mathrm{~min}$ of recording to ensure steady baseline responses, neurons were perfused with an

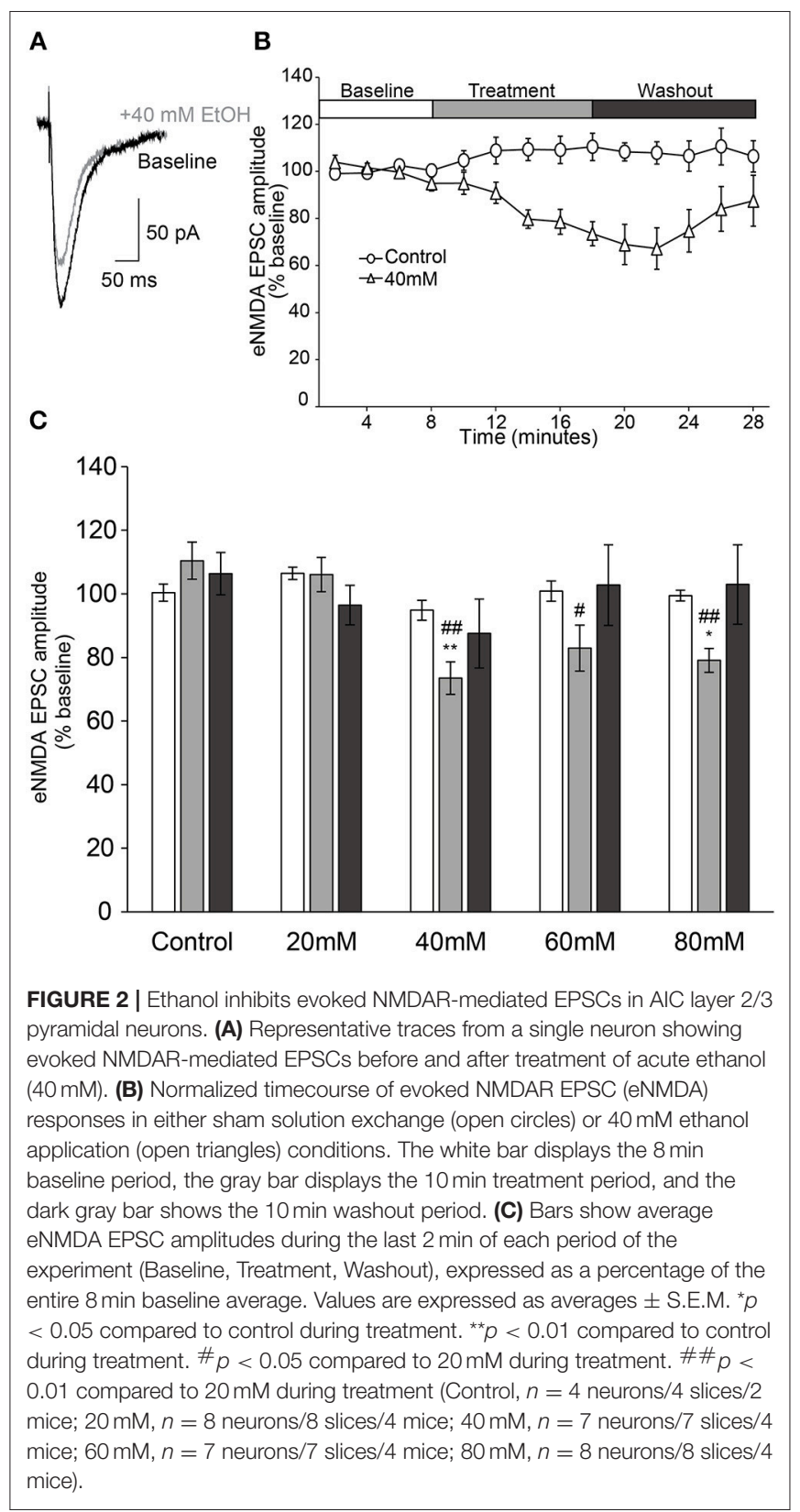

ethanol-containing ACSF for a 10 min treatment period, followed by a 10 min ethanol washout period.

We observed no effect of time or time $\times$ treatment condition interaction on AMPAR-mediated EPSC amplitude over the entire 28 min experiment [Figure 3; two-way repeated measures ANOVA, main effect of time: $F_{(2,37)}=1.9, \mathrm{n} / \mathrm{s}$; time $\times$ treatment interaction: $\left.F_{(6,37)}=1.7, \mathrm{n} / \mathrm{s}\right]$. In the 60 and $80 \mathrm{mM}$ treatment concentrations, there appeared to be a delayed enhancement of peak AMPAR-mediated EPSCs during the last $2 \mathrm{~min}$ of the $10 \mathrm{~min}$ washout period (Figure 3C). However, one-way ANOVA comparing treatment conditions during this time period indicated these enhancements were not statistically significant $\left[F_{(3,20)}=1.44, \mathrm{n} / \mathrm{s}\right]$. 


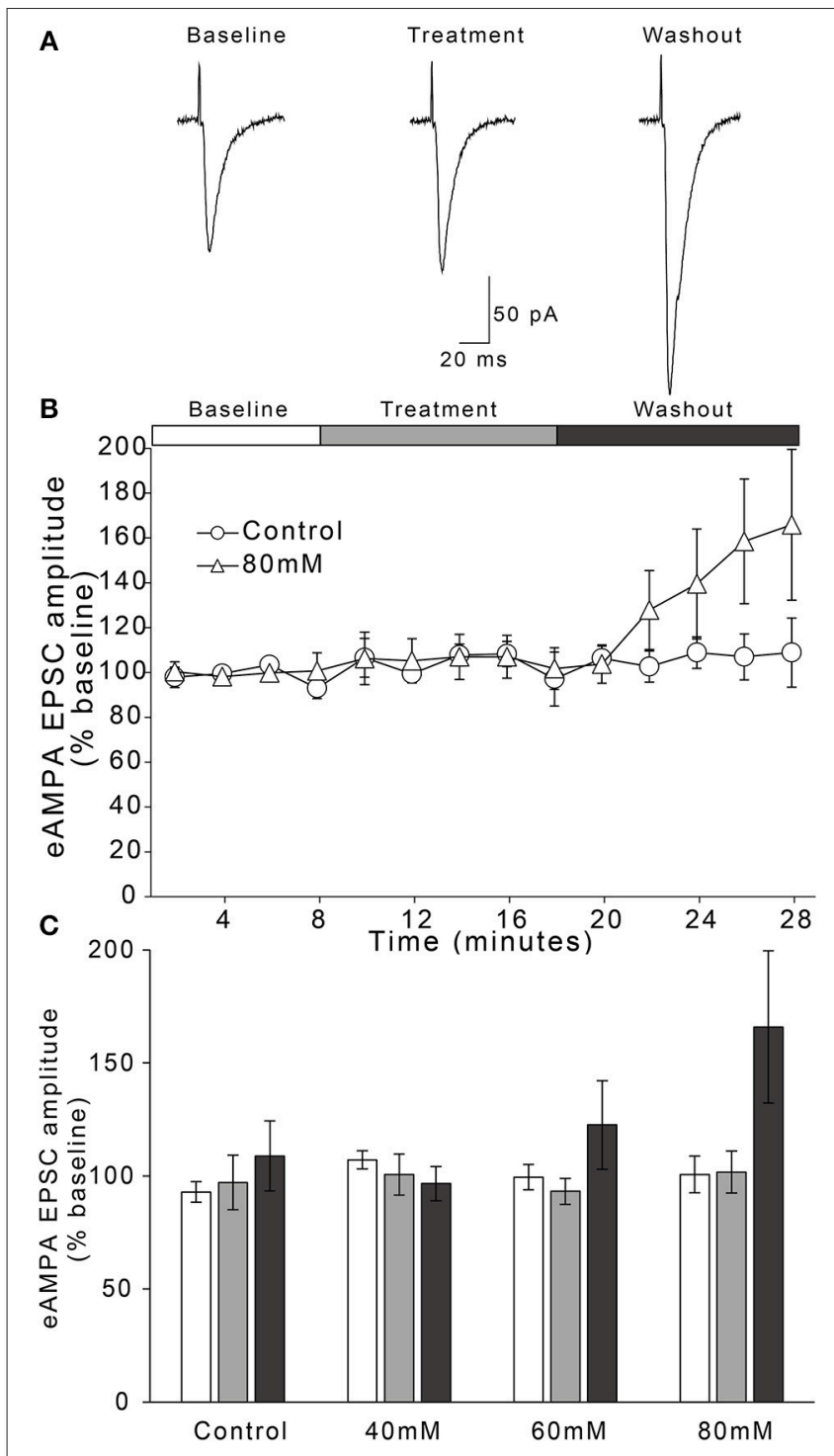

FIGURE 3 | Ethanol has no effect on evoked AMPAR-mediated EPSC amplitudes in AIC layer 2/3 pyramidal neurons. (A) Representative traces from a single neuron showing evoked AMPAR-mediated EPSCs before and after treatment with acute ethanol $(80 \mathrm{mM})$. (B) Normalized timecourse of evoked AMPAR EPSC (eAMPA) responses in either sham solution exchange (open circles) or $80 \mathrm{mM}$ ethanol application (open triangles) conditions. The white bar displays the $8 \mathrm{~min}$ baseline period, the gray bar displays the $10 \mathrm{~min}$ treatment period, and the dark gray bar shows the 10 min washout period. (C) Bars show average eAMPA amplitudes during the last 2 min of each period of the experiment (Baseline, Treatment, and Washout), expressed as a percentage of the entire $8 \mathrm{~min}$ baseline average. Values are expressed as averages \pm S.E.M (Control, $n=4$ neurons/4 slices/3 mice; $40 \mathrm{mM}, n=6$ neurons/ 6 slices $/ 4$ mice; $60 \mathrm{mM}, n=5$ neurons $/ 5$ slices $/ 4$ mice; $80 \mathrm{mM}, n=9$ neurons $/ 9$ slices $/ 7$ mice).

\section{Ethanol-Sensitivity of sEPSCs}

As a final assay of whether ethanol modulates glutamatergic transmission onto layer 2/3 AIC pyramidal neurons, we tested whether acute ethanol modulates spontaneous EPSCs (sEPSCs) in the AIC. Ethanol has been shown to reduce presynaptic

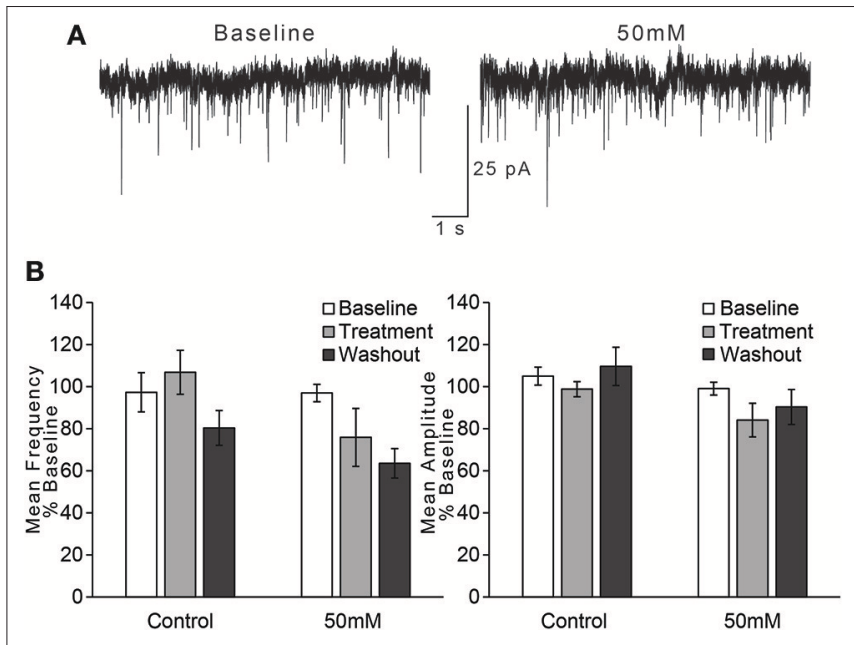

FIGURE 4 | Ethanol has no effect on spontaneous EPSCs in AIC layer 2/3 pyramidal neurons. (A) Representative traces from a single neuron showing spontaneous EPSCs (sEPSCs) before and after treatment with acute ethanol (50 mM). (B) Summary charts showing mean frequency (left) and amplitude (right) of sEPSCs during the last 2 min of each period of the experiment (Baseline, Treatment, and Washout), expressed as a percentage of the entire $10 \mathrm{~min}$ baseline average. Values are expressed as averages \pm S.E.M (Control, $n=8$ neurons $/ 8$ slices $/ 6$ mice; $50 \mathrm{mM}, n=9$ neurons $/ 9$ slices $/ 7$ mice).

glutamate release in multiple brain regions (Lovinger and Roberto, 2013). We assumed that any ethanol-induced changes in sEPSC frequency would be indicative of changes in presynaptic glutamate release, while ethanol-induced changes in sEPSC mean amplitude would be indicative of changes in postsynaptic sensitivity to glutamate (Siggins et al., 2005). Therefore, neurons were voltage-clamped at $-70 \mathrm{mV}$, and sEPSCs were recorded in the presence of $50 \mu \mathrm{M}$ picrotoxin to yield glutamate receptor-mediated spontaneous currents. Following $10 \mathrm{~min}$ of recording to ensure steady baseline responses, neurons were perfused with an ethanol-containing ACSF for a $10 \mathrm{~min}$ treatment period, followed by a $10 \mathrm{~min}$ ethanol washout period.

For the effect of ethanol on mean frequency of sEPSCs, we observed that an effect of time on sEPSC frequency did not vary by treatment condition [Figure 4; two-way repeated measures ANOVA, main effect of time: $F_{(2,30)}=4.2, p=$ 0.025 ; time $\times$ treatment interaction: $\left.F_{(2,30)}=1.41, \mathrm{n} / \mathrm{s}\right] . \mathrm{We}$ also directly compared the two treatment conditions (control vs. $50 \mathrm{mM}$ ethanol) during just the treatment phase of the experiment, but this analysis also did not indicate a statistically significant effect of ethanol: $t_{(15)}=1.756, \mathrm{n} / \mathrm{s}$. Thus, although sEPSC frequency appeared to decrease with the application of $50 \mathrm{mM}$ ethanol, the magnitude of this change was not different than that observed in the control treatment group. For the effect of ethanol on mean amplitude of sEPSCs, we observed no effect of time or interaction of time with treatment condition [Figure 4; two-way repeated measures ANOVA, main effect of time: $F_{(2,30)}=2.3, \mathrm{n} / \mathrm{s}$; time $\times$ treatment interaction: $\left.F_{(2,30)}=0.84, \mathrm{n} / \mathrm{s}\right]$, nor a difference in treatment conditions during the treatment period: $t_{(15)}=1.607$, $\mathrm{n} / \mathrm{s}$. 


\section{Ethanol-Sensitivity of sIPSCs}

In addition to our investigation of the effects of acute ethanol on glutamatergic transmission, we wished to characterize whether ethanol modulates GABAergic transmission in the AIC. Acute ethanol has been shown to modulate GABAergic transmission in several brain regions and experimental preparations (Lovinger and Roberto, 2013). Therefore, we tested whether acute ethanol modulated $\mathrm{GABA}_{\mathrm{A}} \mathrm{R}$-mediated spontaneous IPSCs (sIPSCs) in the AIC. Neurons were voltage-clamped at $-70 \mathrm{mV}$, and sIPSCs were recorded in the presence of $1 \mathrm{mM}$ kynurenic acid to block glutamatergic transmission. Following $10 \mathrm{~min}$ of recording to ensure steady baseline responses, neurons were perfused with an ethanol-containing ACSF for a $10 \mathrm{~min}$ treatment period, followed by a $10 \mathrm{~min}$ ethanol washout period.

For the effect of ethanol on mean frequency of sIPSCs, we observed no effect of time on mean frequency of sIPSCs and no time $\times$ treatment condition interaction [Figure 5; two-way repeated measures ANOVA, main effect of time: $F_{(1,18)}=1.52$, $\mathrm{n} / \mathrm{s}$; time $\times$ treatment interaction: $\left.F_{(1,18)}=0.24, \mathrm{n} / \mathrm{s}\right]$. We also found no difference between treatment conditions (control vs. $50 \mathrm{mM}$ ethanol) during the treatment phase: $t_{(15)}=0.031, \mathrm{n} / \mathrm{s}$. For the effect of ethanol on mean amplitude of sIPSCs, we observed no effect of time on mean amplitude of sIPSCs and no time $\times$ treatment condition interaction [Figure 5; two-way repeated measures ANOVA, main effect of time: $F_{(2,30)}=0.43$, $\mathrm{n} / \mathrm{s}$; time $\times$ treatment interaction: $\left.F_{(2,30)}=1.79, \mathrm{n} / \mathrm{s}\right]$. A separate comparison of just the treatment phase of the experiment also did not reveal a statistically significant difference between control and $50 \mathrm{mM}$ ethanol: $t_{(15)}=1.058, \mathrm{n} / \mathrm{s}$.

\section{LTD in AIC Layer 2/3 in Ethanol-Naïve Mice}

We found that in the presence of $50 \mu \mathrm{M}$ picrotoxin, local low frequency stimulation ( $1 \mathrm{~Hz}$ for $15 \mathrm{~min}$ ) induced long-term depression (LTD) of evoked EPSCs in layer 2/3 AIC pyramidal neurons (Figures 6A,B; one-sample $t$-test, $t=4.622, p=$ 0.0007). To investigate whether the reduction in EPSC magnitude observed was due to either presynaptic changes in glutamatergic release or post-synaptic changes in glutamate receptor sensitivity, we measured paired-pulse ratios ( 2 pulses, $50 \mathrm{~ms}$ apart) before the $10 \mathrm{~min}$ of baseline recording and after the $30 \mathrm{~min}$ of poststimulation in a separate group of neurons. Neurons tested for paired-pulse ratios displayed equivalent post-conditioning EPSC amplitudes to that seen in naïve control neurons (Figure 6B; unpaired $t$-test, $t=0.05, \mathrm{n} / \mathrm{s}$ ). We observed no change in pairedpulse ratios before and after the induction of LTD, indicating that LTD in layer 2/3 AIC neurons is not due to changes in presynaptic glutamate release (Figures 6C,D; paired $t$-test, $t=2.484, \mathrm{n} / \mathrm{s}$ ).

\section{LTD in AIC Layer 2/3 in Ethanol-Naïve Mice Is NMDAR-Dependent and Ethanol Sensitive}

An investigation from Liu and colleagues was the initial demonstration and investigation of LTD in the mouse insular cortex (IC) (Liu et al., 2013). They found via field potential recordings that low frequency stimulation in adult mouse IC can induce LTD of evoked excitatory post-synaptic potentials

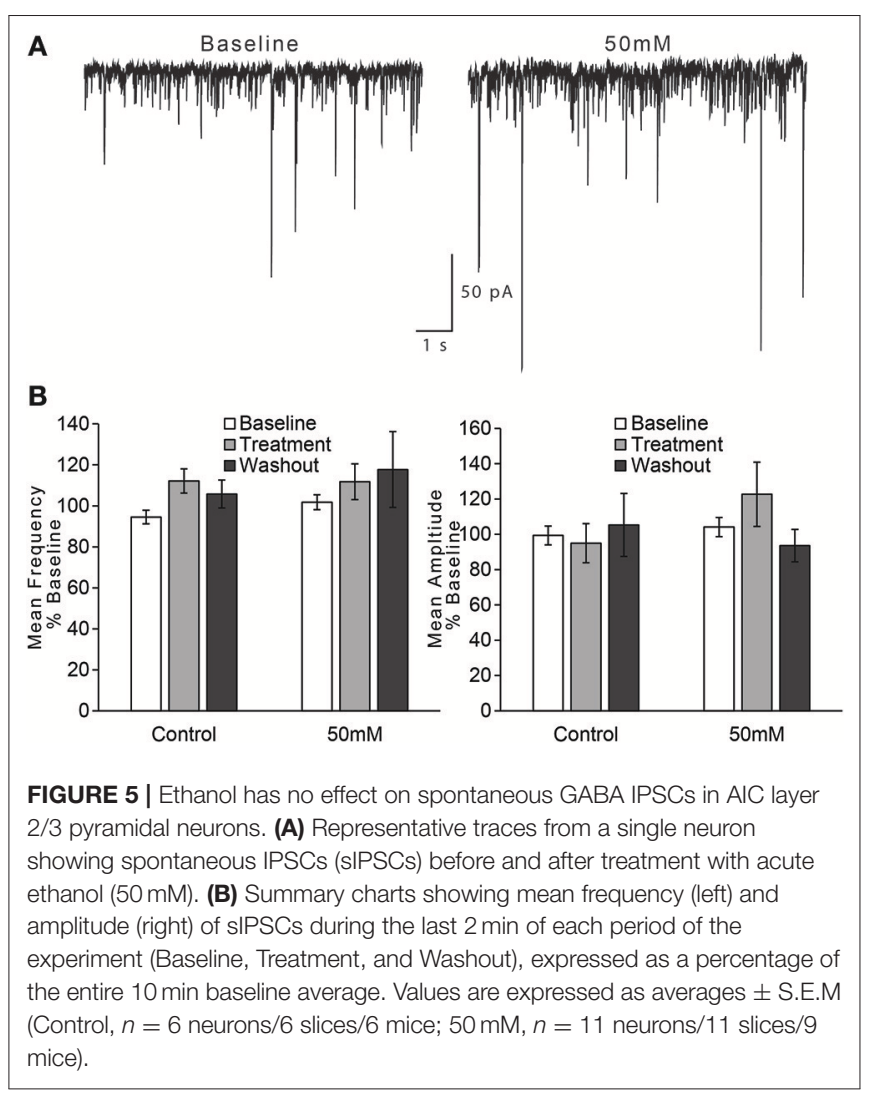

that depends upon NMDAR activation. Since this is the first investigation of whole cell LTD in the IC, we wished to determine whether our observed form of LTD similarly depended upon NMDAR activation. Bath application of the non-selective NMDA receptor antagonist DL-APV $(100 \mu \mathrm{M})$ blocked the expression of LTD (Figure 7; one-sample $t$-test, $t=0.154, \mathrm{n} / \mathrm{s}$ ).

Acute ethanol has been shown to modulate the expression NMDAR-dependent forms of synaptic plasticity in multiple brain regions (McCool, 2011). Therefore, we next tested whether acute pharmacologically relevant concentrations of ethanol modulate the expression of layer 2/3 AIC pyramidal neuron LTD. Bath application of multiple concentrations of ethanol (20, 40, $60 \mathrm{mM})$ did not differ in their ability to block the expression of AIC LTD [Figure 8; one-way ANOVA, $F_{(2,17)}=0.16, \mathrm{n} / \mathrm{s}$ ].

\section{DISCUSSION}

\section{Ethanol Has Multiple Effects on the Glutamate System}

The major findings of this investigation are that acute ethanol has significant effects on glutamatergic transmission and glutamatergic synaptic plasticity in layer 2/3 AIC pyramidal neurons, but little to no effect on GABAergic transmission at the concentration tested $(50 \mathrm{mM})$. Recordings from brain slice preparations across multiple brain regions have generally shown an inhibitory effect of acute ethanol on glutamatergic transmission (Lovinger and Roberto, 2013). This effect is 


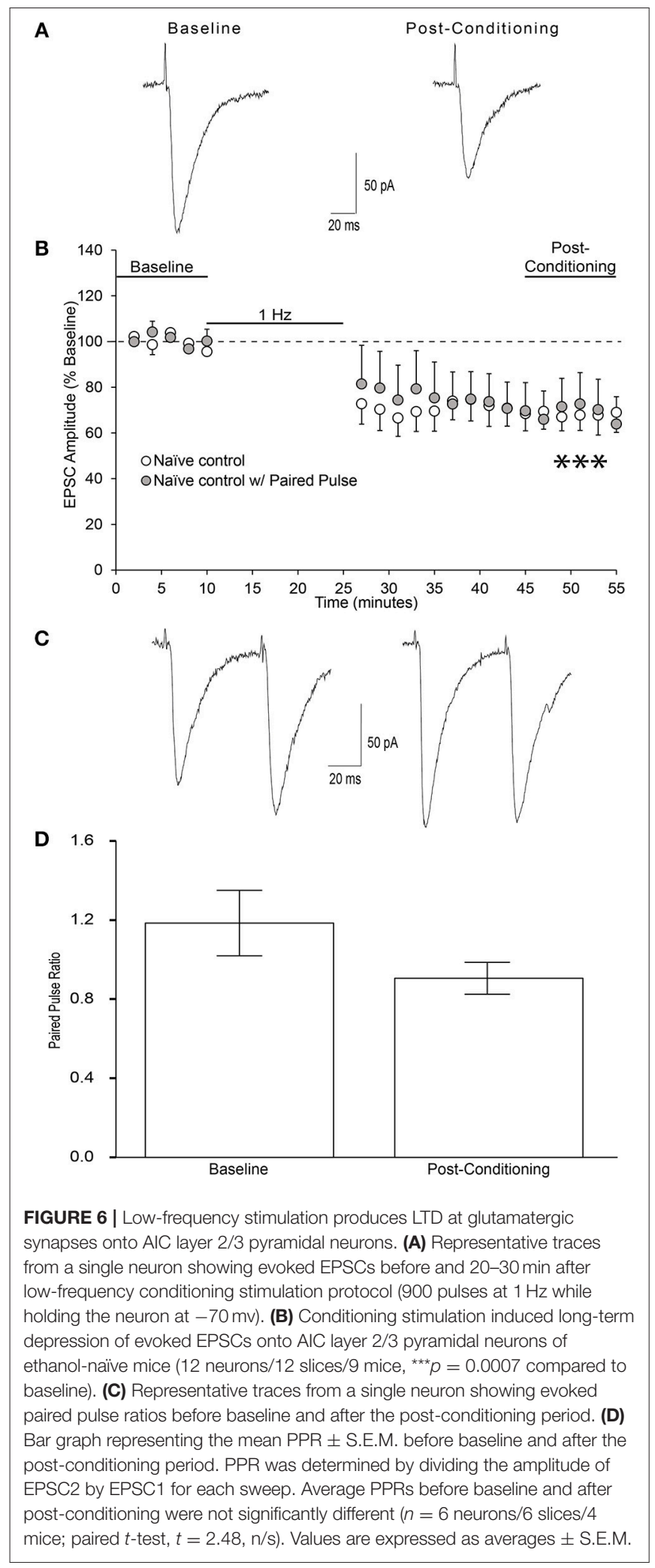

largely attributed to ethanol's inhibitory actions on post-synaptic NMDARs (Ron and Wang, 2009). Since acute ethanol has been shown to modulate glutamatergic transmission across

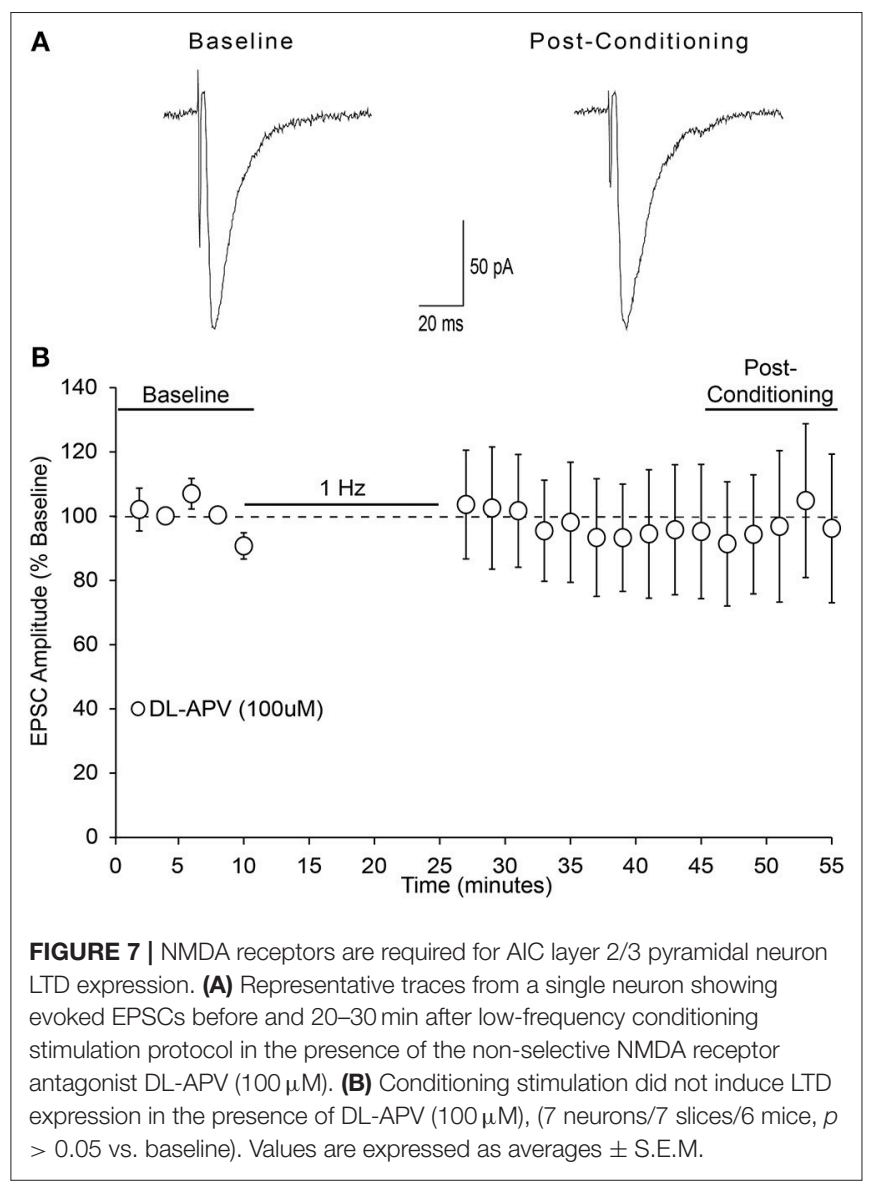

several brain regions and experimental preparations (Lovinger and Roberto, 2013), we wished to determine whether ethanol modulates glutamatergic intracortical processing in the AIC. A commonly replicated synaptic effect of ethanol across multiple brain regions has been its inhibitory action on postsynaptic NMDARs, as ethanol has generally been found to have a concentration-dependent inhibition of NMDAR-mediated transmission (Ron and Wang, 2009). Moreover, ethanol's inhibitory effects on NMDARs and disruption of NMDARdependent signaling processes have been shown to be major canonical mechanisms by which chronic ethanol disrupts healthy brain functioning; NMDAR-dependent synaptic mechanisms of learning and memory have generally been shown to be disrupted by chronic alcohol use and implicated in alcoholrelated phenotypes (Ron and Wang, 2009). For these reasons we tested whether ethanol inhibited post-synaptic NMDARs in layer 2/3 AIC pyramidal neurons. Our investigation determined that ethanol modestly inhibited evoked NMDAR-mediated currents in the AIC in a concentration-related manner. Such a finding complements research in other brain regions which identifies NMDARs as a modest $(\approx 25 \%$ inhibition) ethanol-sensitive target in cortical neurons (Lovinger and Roberto, 2013). However, it is important to consider that no statistically significant inhibition of evoked NMDAR-mediated EPSCs was observed at $20 \mathrm{mM}$, an intoxicating ethanol concentration. Therefore, our data, at initial 


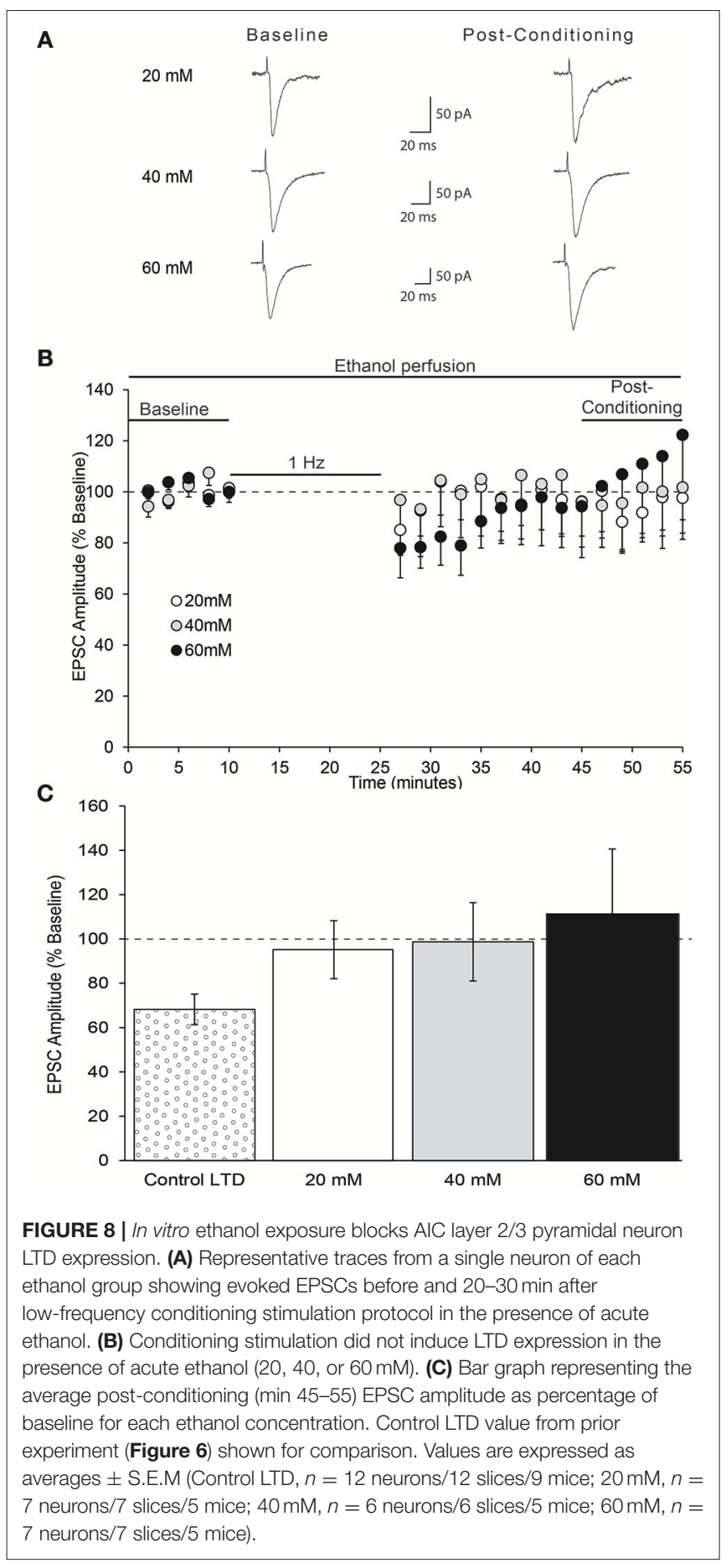

consideration, suggest that the action of ethanol on NMDARs in the AIC is a modest effect observable only at highly intoxicating concentrations ( $\geq 40 \mathrm{mM}$ ) of ethanol.

However, it is possible that ethanol's action on AIC NMDARs in vivo occurs at lower ethanol concentrations and at greater peak inhibition levels than what we observed in the current study due the limitations of a brain slice preparation. For example, a well-established modulator of the degree of ethanol inhibition on evoked NMDAR-mediated responses is the ACSF $\mathrm{Mg}^{2+}$ concentration, as studies have shown that higher $\mathrm{Mg}^{2+}$ concentrations increase the sensitivity of NMDARs to ethanol (Carlton et al., 1998; Ron and Wang, 2009). Prior research investigating ethanol's inhibitory effect on NMDARs utilizing expression systems has shown that the degree of ethanol inhibition of NMDARs is $\mathrm{Mg}^{2+}$-dependent (Jin et al., 2008). Our experimental design utilized a concentration of $\mathrm{Mg}^{2+}$ $(1.0 \mathrm{mM})$ that has been shown to produce significant inhibition of evoked NMDAR currents of pyramidal neurons in the basolateral amygdala (Carlton et al., 1998). Since normal cerebrospinal $\mathrm{Mg}^{2+}$ concentration in healthy people is estimated to be around $1.48 \mathrm{mM}$, due to enhanced free $\mathrm{Mg}^{2+}$ in human cerebrospinal fluid, AIC NMDARs may be more sensitive to the inhibitory effects of ethanol under physiological conditions than under those of our brain slice preparation (Banki et al., 1985).

Nonetheless, even if the modest level of inhibition observed only at higher ethanol concentration levels $(40,60,80 \mathrm{mM})$ in this study fully replicate in vivo conditions, we still maintain that this inhibitory effect is a significant phenomenon by which chronic ethanol exposure likely elicits long-term alterations AIC functioning. NMDARs that display sensitivity to acute ethanol inhibition generally enhance their functioning in response to chronic ethanol exposure as a compensatory mechanism due to ethanol's chronic inhibition, which results in aberrations from homeostatic NMDAR-dependent signaling processes (Roberto and Varodayan, 2017). Prior research from our laboratory, among others, has shown that these long term alterations due chronic ethanol exposure lead to robust changes in expression of NMDAR-dependent plasticity states and ethanol-related behavior (Jeanes et al., 2011, 2014; Abrahao et al., 2013). Thus, our findings suggest that NMDARs and NMDAR-mediated signaling processes in layer 2/3 AIC pyramidal neurons are ethanol-sensitive targets likely to underlie alterations in AIC function after chronic ethanol exposure. Since layer $2 / 3$ is the intracortical processing layer of the AIC, our data suggest that general intracortical processing in the AIC as well as its output to downstream brain regions are sensitive to disruption by chronic ethanol.

In order to test the sensitivity of AMPAR-mediated glutamatergic transmission to ethanol, we examined whether evoked AMPAR-mediated currents were sensitive to ethanol. Our investigation found that evoked AMPAR-currents were insensitive to intoxicating concentrations of ethanol, except for a non-statistically significant delayed enhancement nearly $20 \mathrm{~min}$ after the initial bath application of ethanol at a concentration nearly lethal $(80 \mathrm{mM})$ to intolerant individuals. As such, these negative results on evoked AMPAR-mediated currents are indicative of a selective post-synaptic action of ethanol. However, as a final test of ethanol action on presynaptic glutamate release, we measured whether acute ethanol modulated sEPSCs. We found that the significantly intoxicating concentration of ethanol $(50 \mathrm{mM})$ did not change the mean frequency or mean amplitude of sEPSCs, indicative of no changes in glutamate release probability.

In summary, these findings contribute to the abundance of literature indicating that the effects of acute ethanol on 
glutamatergic transmission in brain slice preparations are brainregion specific and concentration dependent. Acute ethanol has been shown to generally reduce glutamatergic transmission (Lovinger and Roberto, 2013). However, investigations of acute ethanol on glutamatergic transmission in some brain regions, such as the ventral tegmental area, somatosensory cortex, and central amygdala show an ethanol-induced enhancement of glutamatergic transmission ( $\mathrm{Lu}$ and Yeh, 1999; Xiao et al., 2009; Silberman et al., 2015; Herman et al., 2016).

\section{Ethanol Has Little Action on $\mathrm{GABA}_{\mathrm{A}}$ Transmission}

Similar to the glutamate system, modulatory effects of ethanol on $\mathrm{GABA}_{\mathrm{A}}$-mediated transmission in brain slice preparations have depended upon the brain region investigated as well as the ethanol concentration used (Nie et al., 1994; Lu and Yeh, 1999; Roberto et al., 2004). Acute ethanol has generally, but not always been shown to increase GABAergic transmission by both pre and post-synaptic mechanisms (Siggins et al., 2005; Lovinger and Roberto, 2013). However, some studies have shown that GABAergic transmission in cortical regions is relatively insensitive to acute ethanol (Proctor et al., 1992; Soldo et al., 1998; Weitlauf and Woodward, 2008). The current investigation did not show any effects of ethanol on spontaneous $\mathrm{GABA}_{\mathrm{A}}$-mediated transmission. We therefore conclude from our investigation that an intoxicating concentration of ethanol has little, if any, effect on spontaneous $\mathrm{GABA}_{\mathrm{A}}$-mediated transmission onto layer 2/3 AIC pyramidal neurons.

\section{Ethanol Disrupts NMDAR-Dependent Synaptic Plasticity}

Since the disrupted processing of interoceptive stimuli has been suggested to play a role in drug and alcohol use disorders, and synaptic plasticity mechanisms are accepted as underlying aspects of learning and memory, we wished to investigate the effect of ethanol on long-term synaptic plasticity in intracortical processing layers of the AIC. We initially found that acute ethanol inhibits NMDARs in the AIC, and so we hypothesized that any NMDAR-dependent long-term synaptic plasticity measures onto layer 2/3 AIC pyramidal neurons would likely be disrupted by acute ethanol. Therefore, we investigated LTD as a long term synaptic plasticity mechanism onto layer 2/3 AIC pyramidal neurons.

Synaptic plasticity mechanisms are the means by which neural networks adapt to strengthen and weaken their connections to form the basis of information storage and are thought of as mechanisms of learning and memory (Kauer and Malenka, 2007; Kandel et al., 2014). Such synaptic plasticity mechanisms in mesolimbic, addiction-relevant brain regions have been shown to be disrupted by drug experience and are thought to encode for and contribute to future drug and alcohol use (Lüscher and Malenka, 2011; Lovinger and Kash, 2015). Since the AIC and its output have been shown, in animal models, to be involved in more advanced, pathological forms of alcohol drinking, we reasoned that ethanol-induced changes in AIC processing and its output may mediate the changes in interoceptive functioning that are implicated in AUD. Therefore, we decided to investigate plasticity mechanisms in AIC layer $2 / 3$ pyramidal neurons. We performed the first demonstration of LTD using whole cell configuration in the IC. Using a $1 \mathrm{~Hz}$, lowfrequency stimulation protocol, we found a reduction in EPSC magnitude (LTD) of $\sim 34 \%$. This form of LTD was NMDARdependent and likely mediated by a post-synaptic mechanism. Since prior investigation in this study had determined an inhibitory effect of ethanol on NMDARs in AIC 2/3 pyramidal neurons, we reasoned that ethanol may, through its actions on NMDARs, inhibit the expression of our discovered NMDARdependent LTD mechanism. We found that AIC LTD was similarly inhibited by several intoxicating concentrations of acute ethanol (20,40, $60 \mathrm{mM})$, indicating that this NMDAR-dependent plasticity state is highly sensitive to intoxicating concentrations of ethanol.

It is noteworthy that while $20 \mathrm{mM}$ ethanol prevented the expression of LTD, this concentration of ethanol did not inhibit evoked NMDAR-mediated currents. We suggest there are at least three reasons why this could be so. First of all, the difference in ACSF $\mathrm{Mg}^{2+}$ concentration between LTD experiments (1.2 mM) and evoked NMDAR-mediated current experiments (1.0 mM) suggests that NMDARs were sensitive to lower concentrations of ethanol in LTD experiments than in evoked NMDARmediated experiments, as higher $\mathrm{Mg}^{2+}$ concentrations increase the sensitivity of NMDARs to ethanol (Ron and Wang, 2009). Secondly, it is possible that ethanol inhibits our uncovered form of synaptic plasticity via an alternative molecular target than NMDARs. Ethanol in acute preparations has a wide array of molecular targets, and has been shown to inhibit the expression of forms of LTD via its inhibitory action on synaptic metabotropic glutamate receptors (mGluRs) (Carta et al., 2006; Belmequenai et al., 2008; Su et al., 2010; Zorumski et al., 2014). Generally, the major post-synaptic forms of LTD have been shown to be either NMDAR or mGluR-dependent, but some require both NMDARs and mGluRs (Collingridge et al., 2010). Therefore, it is possible that our uncovered form of AIC LTD was additionally mGluRdependent, and that acute ethanol inhibited its expression, at least in part, via its inhibitory actions on mGluRs. Finally, NMDARs have metabotropic actions; thus it is possible that this APV-sensitive LTD is not mediated by ion flux (Dore et al., 2016).

\section{AIC Synaptic Plasticity, Pain, and Alcohol Use Disorder}

Recent research suggests that the neurobiological substrates for pain disorders and addiction overlap, and that adaptations in brain regions involved in chronic pain contribute to alcohol use disorder (Egli et al., 2012). Multiple animal models have implicated NMDAR-depending signaling processes in the IC as targets encoding for chronic pain: The ability to induce IC NMDAR-dependent long-term potentiation and the ability to induce IC NMDAR-dependent LTD in ex vivo slice preparations were each shown to be lost in animal models of chronic 
pain (Qiu et al., 2013; Liu and Zhuo, 2014). This evidence of disrupted IC NMDAR-dependent signaling processes in chronic pain considered alongside ethanol's widely demonstrated disruption of NMDAR-dependent signaling processes suggests that NMDAR-dependent signaling processes in the IC may be shared mechanisms by which both pain and ethanol change IC function. In the present work, we verified that layer $2 / 3$ of the AIC is an additional region in which acute ethanol modulates NMDAR function, and we observed that NMDARdependent plasticity in the AIC is sensitive to intoxicating concentrations of ethanol used to develop alcohol dependence in animal models. Thus, together these findings suggest that processing in the AIC is sensitive to acute ethanol disruption, and that synaptic mechanisms thought to mediate pain-related interoceptive changes in the AIC can also be disrupted by acute ethanol. This is the initial investigation of the molecular mechanisms by which alcohol exposure may change healthy AIC functioning in the development of AUD.

\section{REFERENCES}

Abrahao, K. P., Ariwodola, O. J., Butler, T. R., Rau, A. R., Skelly, M. J., Carter, E., et al. (2013). Locomotor sensitization to ethanol impairs NMDA receptordependent synaptic plasticity in the nucleus accumbens and increases ethanol self-administration. J. Neurosci. 33:11. doi: 10.1523/JNEUROSCI.5839-11.2013

Ade, K. K., Wan, Y., Chen, M., Gloss, B., and Calakos, N. (2011). An improved BAC transgenic fluorescent reporter line for sensitive and specific identification of striatonigral medium spiny neurons. Front. Syst. Neurosci. 8:5. doi: $10.3389 /$ fnsys.2011.00032

Badanich, K. A., Mulholland, P. J., Beckley, J. T., Trantham-Davidson, H., and Woodward, J. J. (2013). Ethanol reduces neuronal excitability of lateral orbitofrontal cortex neurons via a glycine receptor dependent mechanism. Neuropsychopharmacology 38:7. doi: 10.1038/npp.2013.12

Banki, C. M., Vojnik, M., Papp, Z., Balla, K. Z., and Arató, M. (1985). Cerebrospinal fluid magnesium and calcium related to amine metabolites, diagnosis, and suicide attempts. Biol. Psychiatry 20, 163-171.

Belmequenai, A., Botta, P., Weber, J. T., Carta, M., De Ruiter, M., De Zeeuw, C. I., et al. (2008). Alcohol impairs long-term depression at the cerebellar parallel fiber-Purkinje cell synapse. J. Neurophysiol. 100:6. doi: 10.1152/jn.90384.2008

Carlton, J. L., Wilson, W. A., and Moore, S. D. (1998). Magnesium-dependent inhibition of N-Methyl-D-aspartate receptor-mediated synaptic transmission by ethanol. J. Pharmacol. Exp. Ther. 287, 1015-1019.

Carta, M., Mameli, M., and Valenzuela, C. F. (2006). Alcohol potently modulates climbing fiberpurkinje neuron synapses: role of metabotropic glutamate receptors. J. Neurosci. 26, 1906-1912. doi: 10.1523/JNEUROSCI.4430-05.2006

Collingridge, G. L., Peineau, S., Howland, J. G., and Wang, Y. T. (2010). Long-term depression in the CNS. Nat. Rev. Neurosci. 11:7. doi: 10.1038/nrn2867

Dore, K., Aow, J., and Malinow, R. (2016). The emergence of NMDA receptor metabotropic function: insights from imaging. Front. Synaptic Neurosci. 8:20. doi: $10.3389 /$ fnsyn. 2016.00020

Egli, M., Koob, G. F., and Edwards, S. (2012). Alcohol dependence as a chronic pain disorder. Neurosci. Biobehav. Rev. 36:10. doi: 10.1016/j.neubiorev.2012.07.010

Herman, M. A., Varodayan, F. P., Oleata, C. S., Luu, G., Kirson, D., Heilig, M., et al. (2016). Glutamatergic transmission in the central nucleus of the amygdala is selectively altered in Marchigian Sardinian alcoholpreferring rats: alcohol and CRF effects. Neuropharmacology 102, 21-31. doi: 10.1016/j.neuropharm.2015.10.027

Jaramillo, A. A., Randall, P. A., Frisbee, S., and Besheer, J. (2016). Modulation of sensitivity to alcohol by cortical and thalamic brain regions. Eur. J. Neurosci. 44:8. doi: 10.1111/ejn.13374

Jaramillo, A. A., Randall, P. A., Stewart, S., Fortino, B., Van Voorhies, K., and Besheer, J. (2018a). Functional role for cortical-striatal circuitry

\section{AUTHOR CONTRIBUTIONS}

JS and RMo conceived and designed experiments. JS performed the experiments. JS and RMa analyzed the data and interpreted the results. JS and RMa wrote the paper.

\section{FUNDING}

This work was supported by NIAAA awards R01AA15167 (RMo) and U24AA016651 (RMo and RMa), and the Homer Lindsey Bruce and Fred Murphy Jones endowed graduate fellowships (JS).

\section{ACKNOWLEDGMENTS}

The authors wish to thank Heather Aziz, Daniela Carrizales, Benjamin Hong, and Mayrose Porter for their technical assistance.

in modulating alcohol self-administration. Neuropharmacology 130, 42-53. doi: 10.1016/j.neuropharm.2017.11.035

Jaramillo, A. A., Van Voorhies, K., Randall, P. A., and Besheer, J. (2018b). Silencing the insular-striatal circuit decreases alcohol self-administration and increases sensitivity to alcohol. Behav. Brain Res. 348, 74-81. doi: 10.1016/j.bbr.2018.04.007

Jeanes, Z. M., Buske, T. R., and Morrisett, R. A. (2011). In vivo chronic intermittent ethanol exposure reverses the polarity of synaptic plasticity in the nucleus accumbens shell. J. Pharmacol. Exp. Ther. 336:1. doi: 10.1124/jpet.110.171009

Jeanes, Z. M., Buske, T. R., and Morrisett, R. A. (2014). Cell type-specific synaptic encoding of ethanol experience in the nucleus accumbens shell. Neuroscience 277, 184-195. doi: 10.1016/j.neuroscience.2014.06.063

Jin, C., Smothers, C., and Woodward, J. J. (2008). Enhanced ethanol inhibition of recombinant NMDA receptors by magnesium: Role of NR3 subunits. Alcohol. Clin. Exp. Res. 32:6. doi: 10.1111/j.1530-0277.2008.00667

Kandel, E. R., Dudai, Y., and Mayford, M. R. (2014). The molecular and systems biology of memory. Cell 157:1. doi: 10.1016/j.cell.2014.03.001

Kash, T. L., Matthews, R. T., and Winder, D. G. (2008). Alcohol inhibits NR2Bcontaining NMDA receptors in the ventral bed nucleus of the stria terminalis. Neuropsychopharmacology 33:6. doi: 10.1038/sj.npp.1301504

Kauer, J. A., and Malenka, R. C. (2007). Synaptic plasticity and addiction. Nat. Rev. Neurosci. 8, 844-858. doi: 10.1038/nrn2234

Liu, M., Koga, K., Guo, Y., Kang, S. J., Collingridge, G. L., Kaang, B., et al. (2013). Long-term depression of synaptic transmission in the adult mouse insular cortex in vitro. Eur. J. Neurosci. 38:8. doi: 10.1111/ejn.12330

Liu, M., and Zhuo, M. (2014). Loss of long-term depression in the insular cortex after tail amputation in adult mice. Mol. Pain 10:1. doi: 10.1186/1744-8069-10-1

Lovinger, D. M., and Kash, T. L. (2015). Mechanisms of neuroplasticity and ethanol's effects on plasticity in the striatum and bed nucleus of the stria terminalis. Alcohol Res. Curr. Rev. 37:10924.

Lovinger, D. M., and Roberto, M. (2013). Synaptic effects induced by alcohol. Curr. Top. Behav. Neurosci. 13:31-86. doi: 10.1007/7854_2011_143

Lovinger, D. M., White, G., and Weight, F. F. (1990). NMDA receptor-mediated synaptic excitation selectively inhibited by ethanol in hippocampal slice from adult rat. J. Neurosci. 10, 1372-1379.

Lu, S. M., and Yeh, H. H. (1999). Ethanol modulates AMPA-induced current responses of primary somatosensory cortical neurons. Neurochem. Int. 35, 175-183.

Lüscher, C., and Malenka, R. C. (2011). Drug-evoked synaptic plasticity in addiction: from molecular changes to circuit remodeling. Neuron 69:4. doi: 10.1016/j.neuron.2011.01.017

Mangieri, R. A., Maier, E. Y., Buske, T. R., Lasek, A. W., and Morrisett , R. A., (2017). Anaplastic lymphoma kinase is a regulator of alcohol consumption and 
excitatory synaptic plasticity in the nucleus accumbens shell. Front. Pharmacol. 15:8. doi: 10.3389/fphar.2017.00533

McCool, B. A. (2011). Ethanol modulation of synaptic plasticity. Neuropharmacology 61:7. doi: 10.1016/j.neuropharm.2010.12.028

Nie, Z., Madamba, S. G., and Siggins, G. R. (1994). Ethanol inhibits glutamatergic neurotransmission in nucleus accumbens neurons by multiple mechanisms. J. Pharmacol. Exp. Ther. 271, 1566-1573.

Paulus, M. P., and Stewart, J. L. (2014). Interoception and drug addiction. Neuropharmacology 76(Pt B), 342-350. doi: 10.1016/j.neuropharm.2013. 07.002

Proctor, W. R., Allan, A. M., and Dunwiddie, T. V. (1992). Brain region-dependent sensitivity of GABAA receptor-mediated responses to modulation by ethanol. Alcohol. Clin. Exp. Res. 16, 480-489.

Qiu, S., Chen, T., Koga, K., Guo, Y., Xu, H., Song, Q., et al. (2013). An increase in synaptic NMDA receptors in the insular cortex contributes to neuropathic pain. Sci. Signal. 6:275. doi: 10.1126/scisignal.2003778

Renteria, R., Maier, E. Y., Buske, T. R., and Morrisett, R. A. (2017). Selective alterations of NMDAR function and plasticity in D1 and D2 medium spiny neurons in the nucleus accumbens shell following chronic intermittent ethanol exposure. Neuropharmacology 112(Pt A), 164-171. doi: 10.1016/j.neuropharm.2016.03.004

Roberto, M., Madamba, S. G., Moore, S. D., Tallent, M. K., and Siggins, G. R. (2003). Ethanol increases GABAergic transmission at both pre- and postsynaptic sites in rat central amygdala neurons. Proc. Natl. Acad. Sci. U.S.A. 100, 2053-2058. doi: 10.1073/pnas.0437926100

Roberto, M., Schweitzer, P., Madamba, S. G., Stouffer, D. G., Parsons, L. H., and Siggins, G. R. (2004). Acute and chronic ethanol alter glutamatergic transmission in rat central amygdala: an in vitro and in vivo analysis. J. Neurosci. 24, 1594-1603. doi: 10.1523/JNEUROSCI.5077-03.2004

Roberto, M., and Varodayan, F. P. (2017). Synaptic targets: chronic alcohol actions. Neuropharmacology 1:122. doi: 10.1016/j.neuropharm.2017.01.013

Ron, D., and Wang, J. (2009). "The NMDA receptor and alcohol addiction," in Biology of the NMDA Receptor, ed. A. M. Van Dongen (Boca Raton, FL: CRC Press).

Sacks, J. J., Gonzales, K. R., Bouchery, E. E., Tomedi, L. E., and Brewer, R. D. (2015). 2010 National and state costs of excessive alcohol consumption. Am. J. Prev. Med. 49:5. doi: 10.1016/j.amepre.2015.05.031

Scofield, M. D., Heinsbroek, J. A., Gipson, C. D., Kupchik, S. S., Smith, A. C. W., Roberts-Wolfe, D., et al. (2016). The nucleus accumbens: mechanisms of addiction across drug classes reflect the importance of glutamate homeostasis. Pharmacol. Rev. 68:3. doi: 10.1124/pr.116.012484
Seif, T., Chang, S., Simms, J. A., Gibb, S. L., Dadgar, J, Chen, B. T., et al. (2013). Cortical activation of accumbens hyperpolarization-active NMDARs mediates aversion-resistant alcohol intake. Nat. Neurosci. 16:8. doi: 10.1038/nn.3445

Siggins, G. R., Roberto, M., and Nie, Z. (2005). The tipsy terminal: presynaptic effects of ethanol. Pharmacol. Ther. 107, 80-98. doi: 10.1016/j.pharmthera.2005.01.006

Silberman, Y., Fetterly, T. L., Awad, E. K., Milano, E. J., Usdin, T. B., and Winder, D. G. (2015). Ethanol produces corticotropin releasing factor receptor-dependent enhancement of spontaneous glutamatergic transmission in the mouse central amygdala. Alcohol. Clin. Exp. Res. 39:11. doi: 10.1111/acer.12881

Soldo, B. L., Proctor, W. R., and Dunwiddie, T. V. (1998). Ethanol selectively enhances the hyperpolarizing component of neocortical neuronal responses to locally applied GABA. Brain Res. 800, 187-197.

Stahre, M., Roeber, J., Kanny, D., Brewer, R. D., and Zhang, X. (2014). Contribution of excessive alcohol consumption to deaths and years of potential life lost in the united states. Prev. Chronic Dis. 26:11. doi: 10.5888/pcd11.130293

Su, L. D., Sun, C. L., and Shen, Y. (2010). Ethanol acutely modulates mGluR1dependent long-term depression in cerebellum. Alcohol. Clin. Exp. Res. 34:7. doi: $10.1111 / j .1530-0277.2010 .01190$

Weitlauf, C., and Woodward, J. J. (2008). Ethanol selectively attenuates NMDARmediated synaptic transmission in the prefrontal cortex. Alcohol. Clin. Exp. Res. 32:4. doi: $10.1111 /$ j.1530-0277.2008.00625

Xiao, C., Shao, X. M, Olive, M. F., Griffin, W. C., Li, K., Krnjević, K., et al. (2009). Ethanol facilitates glutamatergic transmission to dopamine neurons in the ventral tegmental area. Neuropsychopharmacology 34:2. doi: 10.1038/npp.2008.99

Zorumski, C. F., Mennerick, S., and Izumi, Y. (2014). Acute and chronic effects of ethanol on learning-related synaptic plasticity. Alcohol 48, 1-17. doi: 10.1016/j.alcohol.2013.09.045

Conflict of Interest Statement: The authors declare that the research was conducted in the absence of any commercial or financial relationships that could be construed as a potential conflict of interest.

Copyright (๑) 2018 Shillinglaw, Morrisett and Mangieri. This is an open-access article distributed under the terms of the Creative Commons Attribution License (CC BY). The use, distribution or reproduction in other forums is permitted, provided the original author(s) and the copyright owner(s) are credited and that the original publication in this journal is cited, in accordance with accepted academic practice. No use, distribution or reproduction is permitted which does not comply with these terms. 